Katarina Aladrović-Slovaček

Lidija Cvikić
UDK: UDK: 81`322:821.163.42-93-31Kolarić-Kišur, Z. DOI: http://doi.org/10.21857/y54jof64nm Stručni članak

Rukopis prihvaćen za tisak: 10.5.2017.

\title{
NEKE JEZIČNE OSOBITOSTI MOJE ZLATNE DOLINE NA TEMELJU KORPUSNE ANALIZE TEKSTA
}

\section{Sažetak}

Zbirka autobiografskih pripovijesti Moja Zlatna dolina najuspjelije je i najpoznatije djelo spisateljice Zlate Kolarić-Kišur (rođene u Slavonskome Brodu), koja je u Požegi provela djetinjstvo i dio mladosti. U pripovijestima u kojima kronološki prepričava događaje iz djetinjstva u Zlatnoj dolini, autorica nostalgično dočarava detalje igara, šala, događaja, osoba i krajolika prošloga vremena. Požeškim zavičajnim književnicima Zlata Kolarić-Kišur pripada s obzirom na književno djelo, a njezina je zbirka pripovijesti o djetinjstvu u Zlatnoj dolini na popisu lektire za četvrti razred osnovne škole.

Ovaj se rad bavi nekim obilježjima jezične analize teksta Moje Zlatne doline. Uporabom računalnolingvističkih metoda dobiveni su empirijski podatci o jezičnim obilježjima teksta. Korpusnom analizom pomoću programa NooJ (Silberztein, 2016.) utvrđen je broj pojavnica, leksička gustoća, najčešće sveze riječi i struktura rečenica, kao opisana leksička raznolikost. Rezultati analize i dobiveni korpus uspoređeni su s rezultatima provedene analize romana Čudnovate zgode šegrta Hlapića Ivane Brlić-Mažuranić (Cvikić, Aladrović Slovaček i Bekavac, 2015.), obveznim lektirnim djelom za treći razred osnovne škole.

Ključne riječi: Moja Zlatna dolina; jezična analiza; leksička gustoća; leksička kompetencija; analiza stila.

\section{Uvod}

Zlata Kolarić-Kišur književnica je za djecu koja je pisala drame, romane i pjesme, kojih je velik dio uvršten u časopise, revije i antologije, a neki su stihovi i uglazbljeni. Književni opus i tematiku prilagođavala je aktualnim društvenim temama te ih je pokušala na slikovit i humorističan način, ali uvijek s odgojnom namjerom, približiti svojim mladim čitateljima. Najuspjelije je njezino djelo zbirka autobiografskih pripovijesti Moja Zlatna dolina. U njemu s odmakom od djetinjstva autorica nostalgično prepričava događaje dočaravajući i najmanje detalje. Djelo sadrži i kronološki 
niz sjećanja o značajnim događajima i osobama Požeštine (D. Lerman, F. Ciraki., S. Koydl) te bi ga valjalo uključiti u nastavu književnosti u nižim razredima osnovne škole. Naime, temeljni je cilj nastave hrvatskoga jezika u nižim razredima osnovne škole razvoj jezično-komunikacijske kompetencije, stvaranje čitateljskih navika te poticanje jezičnih djelatnosti slušanja, govorenja, čitanja i pisanja. Stoga je, posebno kada je riječ o lektiri, izuzetno važno ponuditi učenicima naslove koji će ih zainteresirati i poticati njihove čitateljske navike, a koji će im biti bliski i razumljivi. Odabir djela koje će učenici čitati tijekom nastave hrvatskoga jezika treba se temeljiti na različitim načelima, a jedno je od njih zavičajnost (Težak, 1997.). Stoga bi učenike valjalo upoznati s djelima kojih je radnja smještena u njihov zavičaj, odnosno koja su napisali zavičajni pisci. Djelo Moja Zlatna dolina, koje se nalazi na popisu lektire za četvrti razred osnovne škole, važno je uključiti upravo u nastavu hrvatskoga jezika djece o čijem zavičaju djelo govori. Međutim, istraživanje (Aladrović Slovaček i Marić, 2014.) pokazuje da učitelji često ne odabiru djelo Moja Zlatna dolina za lektiru u 4. razredu. Na području Požeško-slavonske županije čita ga sa svojim učenicima tek svaki drugi učitelj. Učitelji navode kako djelo ne obrađuju jer smatraju da je neprimjereno djeci, da je sadržajno dosadno, da ga djeca ne bi razumjela, da ima zanimljivijih književnih djela te da neće pobuditi interes za daljnje čitanje (Aladrović Slovaček i Marić, 2014.). Činjenica da se to djelo sve rjeđe čita, pa čak i u kraju o kojemu autorica u njemu govori - Zlatnoj dolini i gradu Požegi - pokazuje da ga je potrebno približiti učiteljima te pronaći zanimljive načine njegove interpretacije $\mathrm{i}$ približavanja učenicima kako bi ga oni razumjeli i rado čitali, odnosno kako bi kroz njega naučili nešto o svome zavičaju i poznatim zavičajnicima.

\section{O čitanju i čitalačkoj kompetenciji}

Nastava hrvatskoga jezika u osnovnoj školi osobito je usmjerena na razvoj četiriju jezičnih djelatnosti: slušanja, govorenja, čitanja i pisanja. Čitanje je sekundarna jezična djelatnost koja je temelj za usvajanje znanja, ne samo jezičnoga nego i znanja kojim se ovladava u svim ostalim predmetima. Uz pojam čitanja povezuje se pojam čitalačke pismenosti koja se smatra jednom od najvažnijih kompetencija koju učenici stječu u prvim godinama svog obrazovanja. Temelj je za učenje svih predmeta, omogućuje razonodu i osobni razvoj te osposobljava djecu za sudjelovanje u njihovim zajednicama i širem društvu (PIRLS, 2009.). Također, čitalačka se pismenost definira i kao sposobnost razumijevanja, promišljanja i angažmana u pisanim tekstovima radi postizanja osobnih ciljeva, razvoja vlastitoga znanja i potencijala te aktivnoga sudjelovanja u društvu (PISA, 2006.). Posljednjim su PISA istraživanjem provedenim u Republici Hrvatskoj (2006.) kod učenika prvoga razreda srednje škole (15-godišnjaka) čitalačka kompetencija ispitala s obzirom na tri dimenzije: tip 
teksta (neprekinuti, isprekidani), aspekt čitanja (pronalaženje podataka, tumačenje, promišljanje i procjenjivanje) te situacije (osobne, javne, opće, čitanje u obrazovne svrhe). U navedenom je istraživanju Republika Hrvatska zauzela 30. mjesto (od 60 zemalja), a rezultati su pokazali da je $80 \%$ hrvatskih učenika do određene mjere sposobno koristiti se pisanim tekstovima u svrhu razvoja vlastita znanja i potencijala i boljeg sudjelovanja u društvu znanja. Djevojčice su također u svim zemljama, pa tako i u Hrvatskoj, pokazale znatno bolje rezultate od dječaka, a prosječno su imale 40 bodova. Najbolje rezultate pokazali su učenici gimnazija, potom umjetničkih programa, pa strukovnih škola, dok su učenici industrijskog i obrtničkog programa pokazali najlošije rezultate. Istraživanje također pokazuje da su bolje rezultate postigli učenici iz obitelji s boljim ekonomskim, socijalnim i kulturnim statusom; potom učenici kojima je u većoj mjeri dostupna obrazovna oprema kod kuće (knjige za školu, rječnik, tihi kutak za učenje, vlastiti kalkulator); učenici iz obitelji s više kulturnih dobara (umjetničkih djela, klasične književnosti, zbirki poezije) te učenici iz obitelji s većim brojem knjiga. Na rezultate su utjecali i sljedeći parametri: duže korištenje računala; češće korištenje računala; procjena sposobnosti korištenja internetom te uspješnije korištenje računala za izvršavanje zahtjevnijih zadataka.

U PIRLS istraživanju čitalačke pismenosti koje je provedeno 2011. godine u Republici Hrvatskoj sudjelovalo je 5.000 učenika četvrtih razreda, a Republika Hrvatska zauzela je 8 . mjesto od 45 uključenih zemalja. Rezultati toga istraživanja pokazuju da su djevojčice uspješnije od dječaka u svim zemljama, pa tako i u Republici Hrvatskoj (prosjek je 16 bodova, u RH 14 bodova). U Republici Hrvatskoj $11 \%$ učenika postiglo je naprednu razinu u čitanju, a svi su učenici jednako uspješno savladali čitanje književnih djela i čitanje informativnih tekstova. U kategoriji broj sredstava za čitanje u domu hrvatski su učenici na 35. mjestu, a po motiviranosti učenika za čitanje Republika Hrvatska nalazi se u prvoj polovini zemalja (16. mjesto). Mnogi učenici shvaćaju da je čitanje važno kao način učenja, ali ne čitaju iz razonode. Kao i u istraživanju starijih učenika, bolje rezultate postižu učenici obrazovanijih roditelja, uspješniji su u čitanju bili učenici iz većih sredina te učenici koji su minimalno tri godine bili uključeni u vrtićki program. Rezultati učenika iz Republike Hrvatske nešto su bolji od međunarodnog prosjeka i po odgovoru na pitanje imaju li vlastitu sobu i internetski priključak - $64 \%$ učenika ima oboje. Zanimljivo je također da $43 \%$ učenika ima više od 25 knjiga za djecu kod kuće, što je za 16\% manje od međunarodnog prosjeka, a više od 100 knjiga u kućnoj biblioteci ima 16\% učenika, što je za $11 \%$ manje od međunarodnog prosjeka. Unatoč rezultatima navedenih međunarodnih istraživanja, još uvijek nedostaju sustavna istraživanja koja bi donijela iscrpnije spoznaje o čitanju djece školske dobi u Hrvatskoj. Naime, čitalačka kompetencija podrazumijeva razumijevanje pročitanoga teksta, a ono uvelike ovisi o veličini rječnika čitatelja, o jezičnim obilježjima teksta (leksička gustoća, leksička 
raznolikost, sintaktička složenost), o oslanjanju na kontekst, vještini općeg razumijevanja, izvanjezičnome znanju i čitalačkim strategijama (prema: Cvikić, Aladrović Slovaček i Bekavac, 2015.), pa bi sustavno istraživanje čitanja trebalo obuhvatiti i navedena obilježja. Stoga će se korpusnom analizom djela Moja Zlatna dolina utvrditi jezična obilježja koja mogu biti bitan čimbenik razumijevanja teksta za učenike mlađe školske dobi.

\section{Istraživanje}

Za potrebe ovoga rada napravljena je korpusna analiza računalne inačice djela Moja Zlatna dolina (1985., Biblioteka Vjeverica). Za potrebe korpusne analize djelo je skenirano i obrađeno pomoću računalno-lingvističkoga alata NooJ-a (Silberztein, 2016.). Analizirat će se sljedeća obilježja teksta: leksička raznolikost, uporaba glagolskih oblika, najčešće sveze riječi, struktura rečenica i uporaba različitih vrsta rečenica.

\section{Rezultati istraživanja}

Tekst Moja Zlatna dolina sadrži 40.466 pojavnice, od čega su 14.972 različnice. Leksička raznolikost teksta iznosi 0,63. Usporedimo li taj tekst s djelom Čudnovate zgode šegrta Hlapića, koje ima 25.431 pojavnicu i 5.149 različnica (Cvikić, Aladrović Slovaček i Bekavac, 2016.), zaključujemo da je Moja Zlatna duljina brojem pojavnica gotovo dvostruko dulja, a teorijski je moguće da ta dva djela djeca čitaju u razmaku od svega nekoliko mjeseci.

Tekst Moje Zlatne doline omeđen je s 3.077 zareza, 4.279 točaka te 1.077 ostalih pravopisnih znakova (452 uskličnika, 239 upitnika, 316 dvotočja). To znači da ima ukupno 4.970 rečenica, a prosječna je duljina rečenice 8,14 riječi. S obzirom na dob kojoj je knjiga namijenjena, dužina rečenice potpuno je prilagođena jer dijete određene dobi u svojoj rečenici ima +/- jednu riječ u odnosu na broj godina (PavličevićFranić, 2005.). Budući da prosječno dijete četvrtoga razreda ima 10 godina, broj riječi u rečenici potpuno je prilagođen razvojnoj dobi. Najčešće su izjavne rečenice povezane veznikom $i$, odnosno riječ je o nezavisnosloženim rečenicama. Zanimljivo je istaknuti da je, s obzirom na prosječnu duljinu rečenice $(8,14$ riječi), Moja Zlatna dolina, kao lektira za četvrti razred, manje složen tekst za jezičnu obradu na sintaktičkoj razini od Čudnovatih zgoda šegrta Hlapića, djela obvezne lektire za treći razred, u kojemu je prosječna duljina rečenice čak 14,5 riječi (Cvikić, Aladrović Slovaček i Bekavac, 2016.). Tu bi činjenicu valjalo imati na umu prilikom odabira lektire za učenike s poteškoćama u čitanju ili manje uspješne čitače.

U tablici 1 prikazano je dvadeset najčešćih pojavnica, a među prve tri nalazi se pomoćni glagol biti u trećoj osobi jednine - je $(\mathrm{f}=1207)$, veznik $i(\mathrm{f}=1161)$ te povratna 
zamjenica se ( $\mathrm{f}=951)$, koje su ujedno među najčešćim pojavnicama u Hrvatskom nacionalnom korpusu (HKN). S obzirom na opća strukturu teksta na hrvatskome jeziku te podatke iz prethodnih istraživanja (npr. Cvikić, 2016.), očekivano je da će među najčešćim riječima biti prijedlozi $u(f=792)$ i prijedlog $n a(f=497)$, veznici $d a$ $(\mathrm{f}=745)$ i $a(\mathrm{f}=316)$ te glagol biti u prvoj osobi jednine - sam $(\mathrm{f}=486)$ i trećoj osobi množine $-s u(f=336)$ te čestica ne $(\mathrm{f}=244)$. Zamjećuje se da čestotu višu od 1.000 imaju samo pojavnice $j$ e i veznik $i$, dok sve ostale česte pojavnice imaju čestotu manju od 1.000. Od promjenjivih su riječi najčešći različiti oblici glagola biti (je, su, bi, sam) te zamjenice se, mi (f $=266)$ i to $(\mathrm{f}=259)$. Među zamjenicama najčešća je zamjenica $j a \mathrm{u} u$ različitim padežima - dativu, genitivu i instrumentalu $(\mathrm{f}=82)$, kao i posvojna zamjenica moj u nominativu, dativu, genitivu i nominativu množine $(f=224)$. Upotreba navedenih oblika upućuje na prisutnost pripovjedača u tekstu, odnosno na autobiografsku narav djela. Na temu djela upućuju i visoka čestotnost imenica: mama $(\mathrm{f}=$ 103), kuća ( $\mathrm{f}=94)$ i tata $(\mathrm{f}=44)$. Potvrdu prostora u kojemu se cijela radnja događa pokazuje pojavljivanje sintagme Moja Zlatna dolina $(\mathrm{f}=9)$.

Tablica 1. Najčešće pojavnice i različnice u djelu Moja Zlatna dolina

\begin{tabular}{|c|c|c|}
\hline \multicolumn{3}{|c|}{ NAJČEŠĆE POJAVNICE (f) NAJČEŠĆE RAZLIČNICE (f) } \\
\hline $1.207-\mathrm{je}$ & $259-$ to & 103 - mama/mamu/mami/mamom \\
\hline $1.161-\mathrm{i}$ & $252-$ kao & 82 - meni/mene/mnom \\
\hline $951-$ se & $246-\mathrm{za}$ & $224-\mathrm{moj} / \mathrm{mojemu} / \mathrm{mojega} / \mathrm{moga} / \mathrm{moji}$ \\
\hline $792-\mathrm{u}$ & $244-$ ne & 94 - kuća, kući, kuću, kućom \\
\hline $745-$ da & $243-$ što & $44-$ tata/tati/tatom/tatu \\
\hline $497-$ na & $230-s$ & 95 - šešir, šeširi, šeširom \\
\hline 486 - sam & $222-$ bi & 77 - dan/dana/danom \\
\hline $336-\mathrm{su}$ & $212-\mathrm{kad}$ & 46 - vrijeme/vremenu \\
\hline $316-\mathrm{a}$ & 197 - nije & 42 - riječi/riječima/riječi \\
\hline $266-\mathrm{mi}$ & $196-$ od & $34-$ život/životom \\
\hline \multicolumn{3}{|c|}{9 - Zlata, Zlati, Zlatica } \\
\hline & \multicolumn{2}{|c|}{9 - moja Zlatna dolina } \\
\hline
\end{tabular}

Među najčešćim su svezama riječi da se $(\mathrm{f}=88)$, odnosno da je $(\mathrm{f}=86)$ te mi je $(\mathrm{f}=73)$. Navedeni oblici pokazuju da su najčešće sveze s jednim od oblika glagola biti u prvoj i trećoj osobi jednine te trećoj osobi množine. Odabir treće osobe jednine i osobne zamjenice u dativu (mi je) potvrđuje osobnost koja je upisana u ovaj tekst te također potvrđuje da je riječ o djelu koje ima autobiografske elemente. 
Tablica 2. Najčešće sveze riječi

$$
\begin{aligned}
& \text { da se }-88 \\
& \text { da je }-86 \\
& \text { mi je }-73 \\
& \text { je to }-70 \\
& \text { kao da }-64 \\
& \text { sam se }-58 \\
& \text { što je }-43 \\
& \text { se u }-42 \\
& \text { bi se }-39 \\
& \text { su se }-36
\end{aligned}
$$

Kako bi se utvrdila leksička raznolikost koja može utjecati na razumijevanje teksta, napravljena je posebna tekstna analiza kojom su izdvojene riječi za koje se može pretpostaviti da nisu dio aktivnoga rječnika (svih) učenika (tablica 3). To su tuđice poput turcizama (npr. paša, dušman, kapija, pekmez i sl.), hungarizmi (pandur), germanizmi (krajcari) te rusizmi (garav). Neke su od navedenih riječi dio leksika slavonskoga dijalekta kojim se služi kako bi približila svoju priču, događaje i osobe svome čitatelju, pa je očekivano da će tekst bolje razumjeti čitatelji koji su govornici istoga zavičajnoga idioma. Uporaba zavičajnoga idioma očituje se u uporabi ikavice te požeških toponima kojima još jednom potvrđuje mjesto u koje smješta svoju radnju (tablica 3).

\section{Tablica 3. Jezična raznolikost - primjeri}

pekmez, pašaluk, paša, dušman, kajsija, hajde (ajde), kapija (tur.)

pandur (hung.) - policajac, stražar

krajcari (germ.) - sitni novci

mondura (fr.) - uniforma, odora

garav (rus.) - osoba crne kose

dičurlija, bižiš, viverica, zalivati (ikavica)

Šijačija, Grabrik, Jagodnjak, Vučjak, Fratrovica, Tekija, Sokolovac (toponimi)

lakovane, zagrajasmo, šiparica, kudrov (pas) - dijalektalne riječi

Analiza glagolskih oblika pokazala je da je najčešće uporabljen perfekt: npr. stupila je, stvorio je, naučio je; potom prezent: radimo, učimo; pa aorist: vinuše, iskrcaše, a najrjeđe imperfekt: juriše. 
Usporedba djela Čudnovate zgode šegrta Hlapića i Moje Zlatne doline pokazuje da Šegrt Hlapić, obvezna lektira za treći razred, sadrži brojnije arhaizme od teksta Moje Zlatne doline, pa bi, i s obzirom na kriterij leksičke poznatosti, Moja Zlatna dolina učenicima trebala biti bliži tekst.

\section{Zaključak}

Korpusna analiza tekstova koji služe o obrazovne svrhe može donijeti nove spoznaje o obilježjima teksta važnima na njegovo razumijevanje. To je posebno važno za pojedine skupine učenika, poput učenika s teškoćama u učenju ili čitanju. Osim toga, navedene analize mogu donijeti spoznaje i o općoj jezičnoj prikladnosti teksta za učenike pojedine dobi. Provedena analiza djela Moja Zlatna dolina Zlate Kolarić-Kišur pokazala je da je po svojoj jezičnoj raznolikosti i sintaktičkoj strukturi to djelo jezično primjereno djeci četvrtoga razreda osnovne škole. Duljina rečenice i leksička raznolikost primjerene su razvojnoj dobi učenika koji se nalaze u fazi konkretnih misaonih operacija. Upravo zato ova se knjiga ne bi trebala zanemarivati u odabiru knjiga za čitanje, osobito kada je riječ o učenicima kojima je Zlata KolarićKišur zavičajna književnica.

\section{Literatura}

Aladrović Slovaček, Katarina (2014), Autobiografski i zavičajni elementi u stvaralaštvu Zlate Kolarić Kišur i Branka Hribara. U: T. Đurići i I. Mahić (ur.), Veliki dječji knjižeonici/ce kao univerzalni kapital, Slavonski Brod: Učiteljski fakultet Sveučilišta u Osijeku - podružnica Slavonski Brod, str. 30-41.

Cvikić, Lidija (2016), Hrvatski kao ini jezik-odabrane teme. Zagreb: Hrvatsko filološko društvo.

Cvikić, Aladrović Slovaček i Bekavac (2015), Uporaba računalnolingvističkih alata $\mathrm{u}$ istraživanjima obrazovne lingvistike na primjeru korpusne analiza romana Čudnovate zgode šegrta Hlapića. U: Majhut, Berislav, Narančić Kovač, Smiljana i Lovrić Kralj, Sanja (ur.). Šegrt Hlapić od čudnovatog do čudesnog. Zagreb - Slavonski Brod: Hrvatska udruga istraživača dječje književnosti i Ogranak Matice hrvatske Slavonski Brod, str. 269-282.

Kolarić Kišur, Zlata (1985), Moja Zlatna dolina. Zagreb: Biblioteka Vjeverica.

Leppänen, U., Aunola, K. i Nurmi, J. E. (2005), Beginning readers' reading performance and reading habits, U: Journal of Research in Reading, 28(4), str. 383-399. 
Mullis, I. V. S., Martin, M. O., Kennedy, A. M., i Foy, P. (2007), PIRLS 2006 International Report. IEA's progress in international reading literacy study in primary schools in 40 countries. Chestnut Hill, MA: Boston College.

PIRLS - izvješće o postignutim rezultatima iz čitanja (2011), Zagreb: Nacionalni centar za vanjsko vrednovanje.

PISA - prirodoslovne kompetencije za život - izvješće (2006), Zagreb: Nacionalni centar za vanjsko vrednovanje.

Sainsbury, M. i Schagen, I. (2004), Attitudes to reading at ages nine and eleven. U: Journal of Research in Reading, 27, str. 373-386.

Silberztein, Max (2016), Formalizing Natural Languages: the NooJ Approach. Wiley Eds.

Težak, Stjepko (1997), Teorija i praksa nastave hrvatskoga jezika 1 i 2. Zagreb: Školska knjiga.

Wigfield, A. i Guthrie, J. (1997), Relations of children's motivation for reading to the amount and breadth of their reading. U: Journal of Educational Psychology, 89 (3), str. $420-432$.

\section{Language Specificities of Moja Zlatna dolina on the Basis of Text Analysis}

\section{Summary}

The collection of autobiographical stories Moja Zlatna dolina (My Golden Valley) is the most successful and best-known work of the author Zlata Kolarić-Kišur, who was born in Slavonski Brod, and who spent her childhood and a part of her adolescence in Požega. Though the stories were written at a certain time distance from childhood, the author nevertheless nostalgically talks about past events, the details of games, jokes, persons, and the scenery of her childhood. She recollects the significant events and persons in a chronological order, the final event being her departure from the Golden Valley. This is why Zlata Kolarić-Kišur is considered one of local authors of the Požega region, and her collection of stories about her childhood in the Golden Valley has been included among mandatory readings for the fourth grade of primary school, so the teachers can choose to read and analyse it with their pupils. However, the research (Aladrović Slovaček and Marić, 2014) has shown that teachers rarely choose this work, because they consider it uninteresting and inappropriate for the pupils of this age in terms of language and style. Therefore, the objective of this research is to analyse the language and style of My Golden Valley using the programme for computer text analysis - NooJ (Silberztein, 2016). At the linguistic level, the text analysis will determine the number of tokens; lexical density; the most frequent collocations of words and sentence structures; it will moreover describe the varieties of lexis and style. The results of the analysis and the given corpus will be compared with Croatian children's corpus and the results of the analysis of the 
novel The Marvellous Adventures and Misadventures of Hlapić the Apprentice written by Ivana Brlić Mažuranić (Cvikić, Aladrović Slovaček and Bekavac, 2015), which is on the list of mandatory readings for the third grade of primary school. Aiming at achieving the most relevant possible results, the selected language examples will serve as test of lexical competence of the fourth grade pupils $(\mathrm{N}=80)$ in order to determine its level, as well as the receptiveness of pupils for the narrative text My Golden Valley in terms of language and style.

Keywords: My Golden Valley; language analysis; lexical density; lexical competence; style analysis.

Doc. dr. sc. Katarina Aladrović Slovaček Učiteljski fakultet Sveučilišta u Zagrebu Savska 77, 10000 Zagreb

kaladrovic@gmail.com

Izv. prof. dr. sc. Lidija Cvikić

Učiteljski fakultet Sveučilišta u Zagrebu

Savska 77, 10000 Zagreb

lidija.cvikic@ufzg.hr 